\title{
Application of Fourier Transform Infrared Spectroscopy (FTIR) for assessing biogenic silica sample purity in geochemical analyses and palaeoenvironmental research
}

\author{
G. E. A. Swann ${ }^{1}$ and S. V. Patwardhan ${ }^{2}$ \\ ${ }^{1}$ School of Geography, University of Nottingham, University Park, Nottingham, NG7 2RD, UK \\ ${ }^{2}$ Department of Chemical and Process Engineering, University of Strathclyde, James Weir Building, \\ 75 Montrose Street, Glasgow, G1 1XJ, UK
}

Received: 27 July 2010 - Published in Clim. Past Discuss.: 2 September 2010

Revised: 14 January 2011 - Accepted: 14 January 2011 - Published: 9 February 2011

\begin{abstract}
The development of a rapid and non-destructive method to assess purity levels in samples of biogenic silica prior to geochemical/isotope analysis remains a key objective in improving both the quality and use of such data in environmental and palaeoclimatic research. Here a Fourier Transform Infrared Spectroscopy (FTIR) mass-balance method is demonstrated for calculating levels of contamination in cleaned sediment core diatom samples from Lake Baikal, Russia. Following the selection of end-members representative of diatoms and contaminants in the analysed samples, a mass-balance model is generated to simulate the expected FTIR spectra for a given level of contamination. By fitting the sample FTIR spectra to the modelled FTIR spectra and calculating the residual spectra, the optimum best-fit model and level of contamination is obtained. When compared to X-ray Fluorescence (XRF) the FTIR method portrays the main changes in sample contamination through the core sequence, permitting its use in instances where other, destructive, techniques are not appropriate. The ability to analyse samples of $<1 \mathrm{mg}$ enables, for the first time, routine analyses of small sized samples. Discrepancies between FTIR and XRF measurements can be attributed to FTIR end-members not fully representing all contaminants and problems in using XRF to detect organic matter external to the diatom frustule. By analysing samples with both FTIR and XRF, these limitations can be eliminated to accurately identify contaminated samples. Future, routine use of these techniques in palaeoenvironmental research will therefore significantly reduce the number of erroneous measurements and so improve the accuracy of biogenic silica/diatom based climate reconstructions.
\end{abstract}

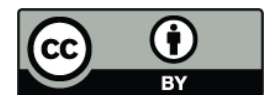

Correspondence to: G. E. A. Swann (george.swann@nottingham.ac.uk)

\section{Introduction}

Increased attention is focused on the potential for geochemical measurements of biogenic silica to be used in palaeoenvironmental research in both continental, riverine, lacustrine and marine settings (e.g., Filippelli et al., 2000; de la Rocha et al., 2000; de la Rocha, 2003, 2006; Derry et al., 2005; Hendry and Rickaby, 2008; Hodson et al., 2008; Opfergelt et al., 2008; Swann et al., 2010). These studies, most commonly involving the analysis of diatoms, plant phytoliths, radiolaria and siliceous sponges, are believed to be particularly important in attempts to better understand the global silicon cycle as well as high latitude environmental change in regions where carbonates are not readily preserved in the sediment record (Conley, 2002; Street-Perrott and Barker, 2008; Leng et al., 2009; Swann and Leng, 2009).

In spite of its potential, the generation of accurate quantitative reconstructions from sources of biogenic silica are often hindered by issues of sample contamination. Sample preparation for foraminifera, ostracods and other biogenic carbonate organisms for geochemical analyses are typically marked by the hand-picking of individual organisms, thereby largely negating issues of contamination. In contrast the smaller size of biogenic silicasamples, and the larger number of organisms consequently needed for a single analysis, typically prevents similar picking although exceptions exist (Hendry et al., 2010). Instead, current methods for purifying/extracting biogenic silica samples involve a mixture of chemical and physical treatment stages including the use of heavy liquids and gravitational split-flow thin fractionation (SPLITT) (e.g., Giddings, 1985; Juillet-Leclerc, 1986; Shemesh et al., 1995; Ellwood and Hunter, 1999; Morley et al., 2004; Rings et al., 2004; Robinson et al., 2004; Hamilton et al., 2005; Tyler et al., 2007; Minoletti et al., 2009). While these techniques can result in the extraction of fully cleaned samples, in most instances a small

Published by Copernicus Publications on behalf of the European Geosciences Union. 
to moderate level of non-removable contaminants will remain. This is particularly apparent in samples where contaminants become electro-statically bound to biogenic silica (Brewer et al., 2008).

Historically the issue of sample contamination in biogenic silica geochemistry measurements has not been widely considered. While spot counts performed under a light or Scanning Electron Microscope (SEM) are increasingly being employed (Morley et al., 2004), the accuracy of these checks has been questioned due to their dependency on the amount of material screened and the difficulty in accurately converting observations into usable estimates of biogenic silica biovolume/contaminant content (Brewer et al., 2008). Recent research has shifted towards employing trace element geochemistry as a measure of contamination. This includes the use of dissolution experiments to take advantage of the different digestion rates for biogenic silica and contaminants (Ellwood and Hunter, 1999; Hendry and Rickaby, 2008) or $\mathrm{X}$-ray Fluorescence (XRF) in which the ionisation of a sample leads to the production of X-rays that are characteristic of the analysed sample (Brewer et al., 2008). Whereas the latter permits direct measurement of contamination by comparing measured oxide concentrations such as $\mathrm{Al}_{2} \mathrm{O}_{3}$ and $\mathrm{CaO}$ to published diatom concentrations (e.g., Mackay et al., 2011a), the relatively large, $0.1-1.0 \mathrm{~g}$, amounts of material required for a single analysis is often prohibitive for the technique to be used in routine analyses. One solution is the use of SEM plus Energy Dispersive X-ray Spectroscopy (EDS). However, as with XRF, EDS analyses can be severely limited in quantifying certain low energy X-rays such as nitrogen and other trace elements.

An alternative is the use of Fourier Transform Infrared Spectroscopy (FTIR), which is both rapid, non-destructive and requires small, $<1 \mathrm{mg}$, sized samples. Chemical bonds vibrate at a characteristic frequency representative of their structure, bond angle and length. Accordingly, individual molecules have the ability to interact with incident radiation by absorbing the radiation at specific wavelengths. FTIR spectroscopy takes advantage of this by recording the energy absorption of a sample over a range of frequencies. Individual absorption peaks can then be identified and assigned to individual chemical bonds to qualitatively or quantitatively identify individual compounds in complex systems. Although solid state characterisation of silica and silicates obtained from biology, minerals and synthetic materials has been performed using XRF and FTIR in conjunction with one another, a direct comparison of the results pointing out the key features of each technique together with their advantages and limitations has not yet been reported (Temuujin et al., 2001; Nayak and Singh, 2007; Liu et al., 2007; Dwivedi et al., 2010).

Applications of FTIR have been widely used to assess the chemical structure of biogenic silica (see summary in Leng et al., 2009) as well as issues of silica maturation, increasing the proportion of $Q_{4}\left[\mathrm{Si}-(\mathrm{O}-\mathrm{Si})_{4}\right]$ to $Q_{3}\left[\mathrm{HO}-\mathrm{Si}-(\mathrm{O}-\mathrm{Si})_{3}\right]$ bonds
(Schmidt et al., 2001; Moschen et al., 2006) and dissolution in diatoms (Rickert et al., 2002; Loucaides et al., 2010). While FTIR data has also been integrated via transfer functions to measure nitrogen, biogenic silica as well as organic and inorganic carbon concentrations in sedimentary records (Vogel et al., 2008; Rosén et al., 2010), this approach requires a training-set to be developed containing samples ranging in purity from $0-100 \%$. With the contamination matrix in cleaned biogenic silica samples likely to vary between individual sites and with the need to develop a stand-alone technique suitable for analysing small samples that can not be first assessed by other geochemical methods in order to develop a training set, an alternative approach is required. Here we have developed a rapid stand-alone FTIR mass-balancing calibration method for measuring contamination in biogenic silica samples and assessed its potential in a sedimentary diatom record from Lake Baikal, Russia. With all samples previously analysed for contamination using XRF, employed here as an absolute measure of sample contamination (Mackay et al., 2011b), a direct comparison of the two techniques can be undertaken and the advantages/disadvantages of the proposed FTIR method assessed. This novel approach provides the first direct quantitative comparison of silica and silicates studies using XRF and FTIR with applications in geo/biochemical and palaeoenvironmental studies of minerals and biominerals.

\section{Methods}

\subsection{Samples}

For the purpose of this study two purified diatom samples are used as diatom end-members, assumed to be representative of clean fossilised diatom material. The first, $\mathrm{BFC}_{\text {mod }}$, is the NERC Isotope Geosciences Laboratory (NIGL) withinlaboratory diatom standard originating from a lacustrine diatomite deposit in California. The second is the marine diatom standard PS1772-8 from the South Atlantic Ridge. Diatoms in both samples are well preserved and show no signs of diagenesis or frustule dissolution (Chapligin et al., 2011). Whereas trace levels of contamination have been detected through XRF and light microscopy in $\mathrm{BFC}_{\bmod }$, no impurities have been found in PS1772-8 with additional SEM, light microscopy, X-ray Diffraction (XRD) and Nuclear Magnetic Resonance (NMR) analyses confirming the purity of both samples (Chapligin et al., 2011).

Analysed samples $(n=78)$ are lacustrine diatoms from Lake Baikal, Russia, ranging in age from $112.4 \mathrm{ka}$ BP to $133.0 \mathrm{ka}$ BP (Marine Isotope Stages [MIS] 5e-6). All have been analysed for diatom oxygen isotopes $\delta^{18} \mathrm{O}_{\text {diatom }}$ following the application of conventional cleaning techniques to remove non-diatom material with sample purity assessed via XRF with aluminium used as a tracer of contamination (Mackay et al., 2011b). A contaminant end-member, 


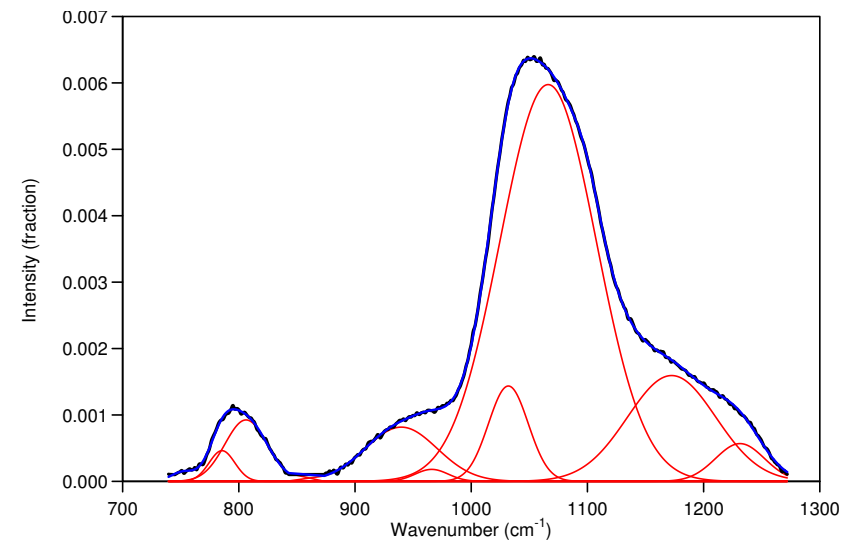

Fig. 1. Example of gaussian peak fitting (red curves) for the $\mathrm{BFC}_{\text {mod }}$ FTIR spectra (Table 1). The resultant fitted model is subsequently used to develop the $\mathrm{BFC}_{\bmod }$ - "Silt" mass-balance calibration.

assumed to be representative of that present in the "cleaned" Lake Baikal diatom material, subsequently referred to as "Silt", was obtained for three samples by dissolving the diatoms in $\mathrm{NaOH}$ and retaining the residue.

\subsection{FTIR analysis}

Previous analyses of diatom/biogenic silica samples with FTIR have involved the creation of a $\mathrm{KBr}$ pressed pellet (Fröhlich, 1989). Since a sample can not be easily retrieved from a pressed pellet, this approach was not followed to avoid losing material. Instead samples were analysed using single-bounce Attenuated Total Reflection FTIR (ATR-FTIR) where raw material is placed directly onto the diamond crystal for data acquisition. Samples data were recorded using a PerkinElmer Spectrum 100 and collecting eight scan from $380-4000 \mathrm{~cm}^{-1}$ with a resolution of $2 \mathrm{~cm}^{-1}$. The data was post-analytical processed using fityk version 0.8.8 (Marcin, 2009).

FTIR spectra of pure silica typically exhibits peaks in two distinct regions (Fidalgo and Ilharco, 2001; Patwardhan et al., 2006): peaks at $>2500 \mathrm{~cm}^{-1}$ and $<1300 \mathrm{~cm}^{-1}$. The first region corresponds to hydroxyl $(-\mathrm{OH})$ stretching from absorbed or molecular water, while the second region occurs due to several silica modes. While containing a number of peaks, the silica region can be primarily separated into three peaks centred at: $\sim 450 \mathrm{~cm}^{-1}, \sim 800 \mathrm{~cm}^{-1}$ and a broad peak at $\sim 1100 \mathrm{~cm}^{-1}$ (Fig. 1; Table 1). The absorption at $\sim 450 \mathrm{~cm}^{-1}$ has been assigned to rocking motion of oxygen atoms bridging silicon atoms in siloxane bonds (Si-O-Si). The symmetric vibrations of silicon atoms in a silixane bond occur at $\sim 800 \mathrm{~cm}^{-1}$ and are termed as $v_{\text {as }}{ }^{-}$ $\mathrm{Si}-\mathrm{O}-\mathrm{Si}$. The largest peak observed in a silica spectrum is present at $\sim 1100 \mathrm{~cm}^{-1}$ and is dominated by antisymmetric motion of silicon atoms in siloxane bonds $\left(v_{\mathrm{as}}-\mathrm{Si}-\mathrm{O}-\mathrm{Si}\right)$. This broad peak consists of three components: (i) a broad shoulder
Table 1. Peak information for the $\mathrm{BFC}_{\text {mod }}$ FTIR spectra in Fig. 1.

\begin{tabular}{rr}
\hline Peak Centre $\mathrm{cm}^{-1}$ & $\begin{array}{r}\text { Area } \\
\end{array}$ \\
\hline 751.78 & 0.35 \\
785.49 & 1.28 \\
806.18 & 4.21 \\
939.82 & 6.32 \\
965.97 & 0.64 \\
1031.96 & 6.16 \\
1066.18 & 62.02 \\
1100.26 & 0.91 \\
1172.48 & 15.19 \\
1231.31 & 3.09 \\
\hline
\end{tabular}

centred at $1115-1130 \mathrm{~cm}^{-1}$ assigned to longitudinal optical mode (LO $v_{a s}-\mathrm{Si}-\mathrm{O}-\mathrm{Si}$ ); (ii) a strong peak centred at 1035$1045 \mathrm{~cm}^{-1}$ (transverse optical mode TO $v_{\mathrm{as}}-\mathrm{Si}-\mathrm{O}-\mathrm{Si}$ ); and (iii) a weak absorption at $950 \mathrm{~cm}^{-1}$ due to silanol (Si-OH) stretching vibrations.

With other wavenumbers dominated by a high noise to signal ratio, this manuscript focuses on the silica region between $700-1300 \mathrm{~cm}^{-1}$ where the main spectral peaks for both end-members were observed. Following baseline correcting all spectra to zero, performed using linear interpolation and selection of zero values at minima in peak intensities, wavenumbers outside the range of $700-1300 \mathrm{~cm}^{-1}$ were therefore removed from the dataset to increase the signal:noise ratio. After normalisation of the spectra to enable the comparison of individual samples, peak deconvolution using gaussian peak fitting was performed on the diatom and "Silt" end-members with the resultant fitted models (Fig. 1), $\mathrm{mBSi}$ and mSilt respectively, extracted for use in the calibration models (Sect. 2.3). For the Baikal "Silt" samples, spectra were mean averaged prior to peak fitting to produce a single contaminant end-member model.

\subsection{FTIR mass-balancing}

By assuming that the spectrum of any Lake Baikal sample reflects the weighted relative abundance of the diatom and "Silt" end-member spectra, a mass-balanced matrix (T) can be created for each diatom/"Silt" end-member combination to define the spectrum expected for a given fraction of contamination, $c$, and diatoms $(1-c)$ in a sample at wavenumber $w$ (Fig. 2):

$\mathbf{T}=[(1-c) \operatorname{mBSi}(w)+$

$(c) \operatorname{mSilt}(w)]_{w=700,700.5,701, \ldots .1300: c=0,0.0001,0.0002, \ldots, 1}$

Following construction of T, measured FTIR spectra for each Lake Baikal sample are fitted against each modelled spectrum, $\left.\mathbf{T}^{*}, c\right]$, with the distance between the measured and modelled spectra, Residual ${ }_{c}$, used to calculate the goodness 

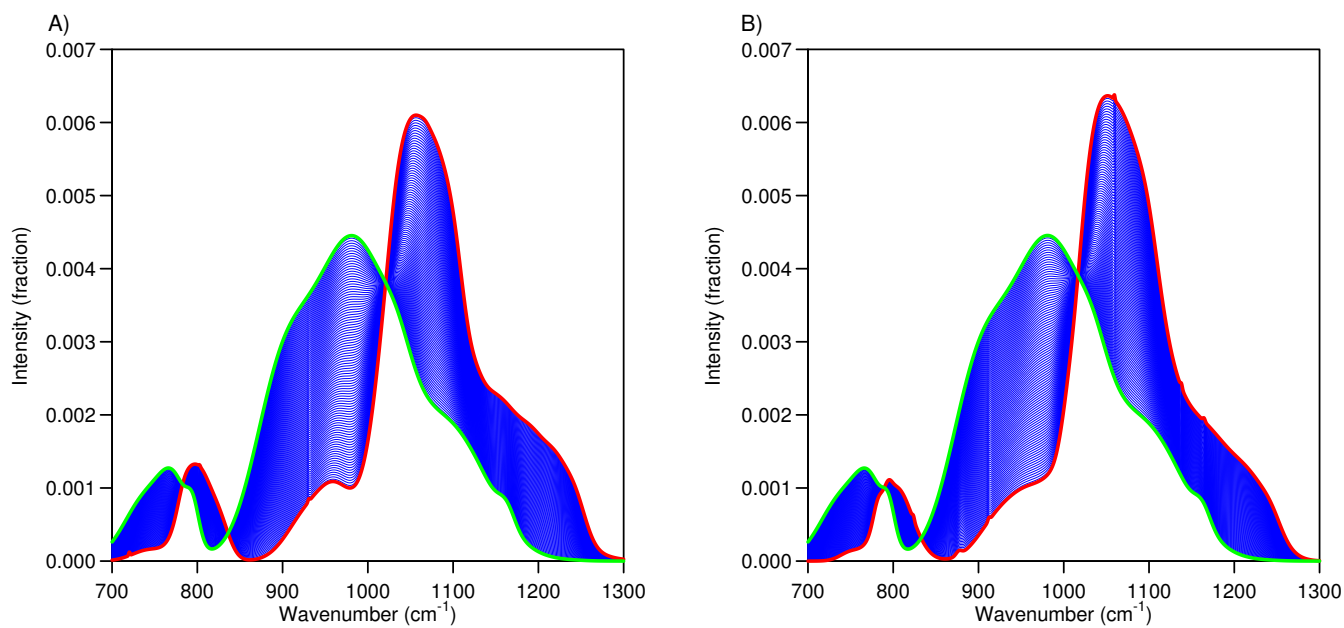

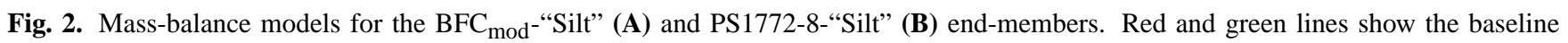
corrected FTIR spectra for the pure diatom and "Silt" end-members respectively. Blue lines show the expected modelled spectra for samples containing different proportions of diatoms/contaminants. Samples containing 100\% diatoms/contaminants are expected to plot on the diatom/“Silt" end-member spectra respectively. As the proportion of diatoms in the sample decreases, sample FTIR spectra are expected to progressively plot away from the red, pure diatom, spectra towards the green, pure "Silt", spectra.

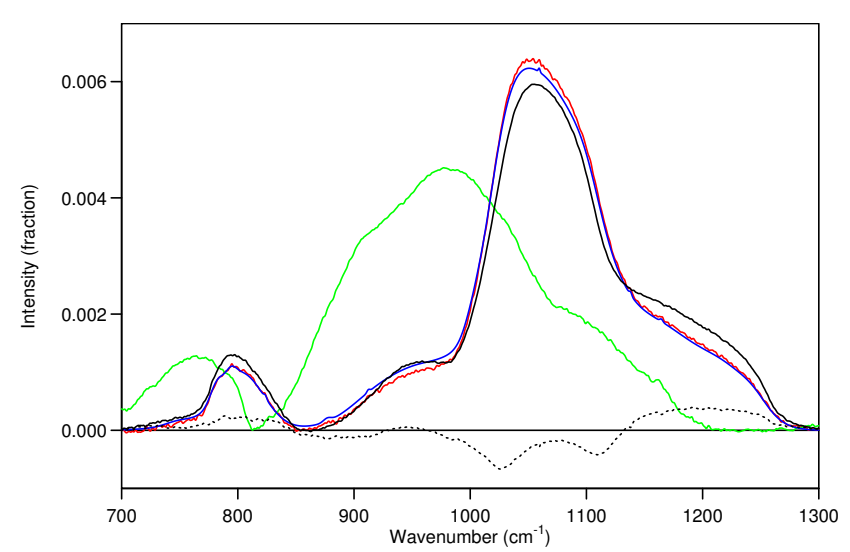

Fig. 3. Example of a Baikal diatom sample (\#36) fitted against the $\mathrm{BFC}_{\text {mod }}$ - "Silt" mass-balance matrix. Red line $=\mathrm{BFC}_{\text {mod }}$ spectra, Green line = "Silt" spectra, Black line = Baikal sample \#36 spectra; Blue line =optimum, best fit, modelled spectra for sample \#36 in the $\mathrm{BFC}_{\text {mod }}$ - "Silt" matrix; Dashed line= residual spectra from the fitting of the \#36 spectra against the modelled spectra. For \#36 $\mathrm{XRF}$ contamination $=6.1 \%$, FTIR contamination $=3.8 \%$.

of fit and so the proportion of the measured spectra not accounted for by the modelled spectra, for a given level of contamination:

$\operatorname{Residual}_{c}=\sum_{w=700}^{1300} \sqrt{\left(\text { Sample }_{w}-\mathbf{T}[w, c]\right)^{2}}$

where Sample $_{w}$ is the spectra of the sample at wavenumber $w$. The optimum best fit model for each sample, and amount of contamination, is identified by the fitted model with the lowest value of Residual (Fig. 3).

\section{Results}

\subsection{Reproducibility}

FTIR analyses of different aliquots of a single sample typically produce identical spectra. In some instances, usually in samples containing higher amounts of contamination, variable spectra are observed. Following model fitting the mean analytical reproducibility $(1 \sigma)$ from these aliquots in terms of contamination is $<1 \%$ for samples containing less than $10 \%$ XRF contamination, $6 \%$ for samples containing 10 $15 \%$ XRF contamination and $12 \%$ for more heavily contaminated samples. This variability in the FTIR spectra is apparent across all wavelengths, in cleaner samples being focused around the main spectral peak at $\sim 1100 \mathrm{~cm}^{-1}$ and centred over the main spectral "contaminant" peaks in more contaminated samples. Combined with the small sample sizes required for FTIR analysis, $<1 \mathrm{mg}$, this poor reproducibility can in part be attributed to the poor homogenisation of sample contaminants and diatoms. To avoid homogenising by grinding, which may cause problems in subsequent sample preparation stages as well as geochemical/isotopic analyses and taxonomic identification, up to three aliquots were analysed per sample with the mean spectra used in subsequent calculations. The good reproducibility for samples containing only small amounts of contamination is more than sufficient for FTIR to be used in obtaining accurate estimates of contamination in these samples. Conversely, evidence of large variability in a sample FTIR spectra would be qualitative evidence of significant levels of impurities in the analysed sample. 


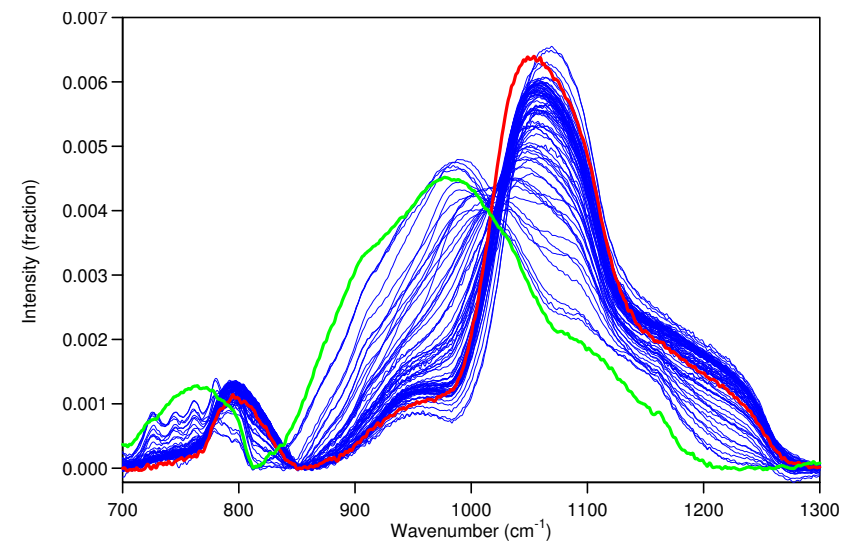

Fig. 4. Comparisons of the Lake Baikal FTIR sample spectra (blue lines) against the $\mathrm{BFC}_{\text {mod }}$ (red line) and "Silt" (green line) spectra. Spectra of contaminated samples are either aligned to the "Silt" spectra or to a mixture of the diatom/“Silt" spectra.

\subsection{FTIR spectra}

FTIR analysis of the three contaminant samples that make up the "Silt" end-member produce near identical spectra, validating the approach here of combining the three samples to create a single "Silt" contaminant end-member. Significant variability between these samples would have suggested the existence of different contamination matrices between individual samples, requiring the creation of FTIR models including two or more contaminant end-members (see Sect. 3.3). Comparisons of the FTIR spectra for the diatom standards $\mathrm{BFC}_{\mathrm{mod}}$ and PS1772-8 against "Silt" illustrates the significant differences between the end-members (Fig. 2). Accordingly, qualitative analysis of the Lake Baikal sample spectra against these end-members before calculation of $\mathrm{T}$

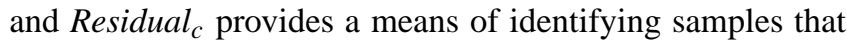
are significantly distorted away from the $\mathrm{BFC}_{\bmod } / \mathrm{PS} 1772-8$ spectra and so heavily contaminated by non-diatom components (Fig. 4).

\subsection{Model fitting}

Application of the two end-member FTIR models $\left(\mathrm{BFC}_{\bmod ^{-}}\right.$ "Silt" and PS1772-8-"Silt") to the Lake Baikal samples produces results that are broadly similar to those achieved using XRF, although significant over and under estimation is apparent for some samples (Fig. 5a, b). Although $\mathrm{XRF}$ analyses indicate small levels of contamination in BFC $\left(\mathrm{Al}_{2} \mathrm{O}_{3}=2.0 \mathrm{wt} . \%\right)$ compared to PS1772-8 $\left(\mathrm{Al}_{2} \mathrm{O}_{3}=\right.$ 0.09 wt.\%) (Chapligin et al., 2011), using the PS1772-8 end-member only marginally reduces the difference between XRF and FTIR estimates of contamination. However, values of Residual for PS1772-8-"Silt" are significantly lower at c. 5\% for most samples, suggesting that the PS17728 end-member produces more accurate results with better identification of the optimal FTIR model (Fig. 5c). Typ-

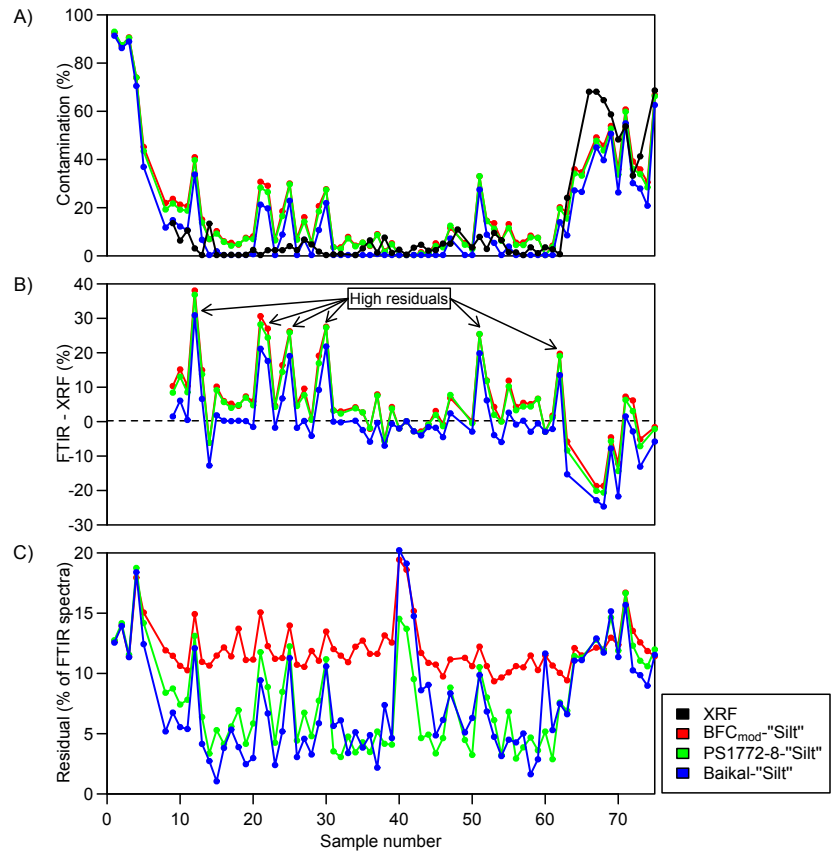

Fig. 5. FTIR two end-member results: (A) FTIR and XRF estimates of contamination in Lake Baikal samples; (B) FTIR minus XRF estimates of contamination. Positive/negative values indicate FTIR over/under-estimation of sample contamination; (C) Residuals $\left(\right.$ Residual $\left._{C}\right)$ from the fitting of the sample FTIR spectra against the best-fit modelled FTIR spectra. No XRF results for some samples indicates the absence of sufficient material for XRF analysis.

ically, samples with residual values above $7 \%$ are marked by increased offsets between FTIR and XRF. In an attempt to reduce Residual $_{c}$ and so improve the accuracy of the FTIR contamination estimates, a three end-member training set was constructed consisting of $\mathrm{BFC}_{\mathrm{mod}}$ or PS1772-8 and standards of mica and montmorillonite $\left(\mathrm{BFC}_{\bmod }-\mathrm{Mica} / \mathrm{Mont}\right.$ and PS1772-8-Mica/Mont) to reflect the composition of the clay mineralogy in the Lake Baikal sediment record (Fagel and Mackay, 2008) (Fig. 6). While values of Residual ${ }_{c}$ are marginally lower under these three end-member models with a slight improvement occurring in the accuracy of the $\mathrm{BFC}_{\text {mod }}$-Mica/Mont model relative to XRF, no significant improvement occurs for PS1772-8-Mica/Mont when compared to the original PS1772-8-“Silt" model (Fig. 7).

\section{Discussion}

\subsection{End-member selection}

\subsubsection{Diatom end-member}

Ideally end-members should be selected so as to be fully representative of the sample matrix. A notable feature of both the $\mathrm{BFC}_{\text {mod- }}$ "Silt" and PS1772-8-"Silt" models are the wide range of Residual ${ }_{c}$ values from $2.8-19.4 \%$. With sample 


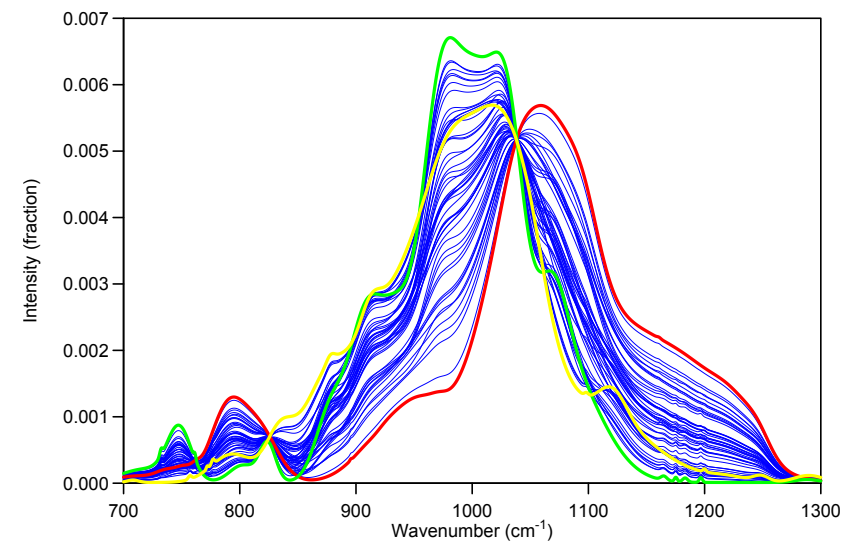

Fig. 6. Example three end-member model showing FTIR spectra for the Baikal diatom end-member (red line), mica (green line) and montmorillonite (yellow line). Blue lines show the expected spectra for samples containing different proportions of diatoms/contaminants. As the proportion of diatoms decreases, spectra are expected to progressively plot away from the pure diatom spectra and towards the mica/montmorillonite spectra. For clarity only a random 50 out of the 5151 (at $1 \%$ resolution) possible endmember spectra combinations are shown.

tests confirming the purity of the diatom end-members, this suggests that the individual diatom/contaminant endmembers are not fully representative of those in the Lake Baikal samples. Repeating the FTIR model calculations using a diatom end-member created from the five cleanest Lake Baikal diatom samples, based on XRF measurements which indicate no contamination in these samples, results in significantly lower values of Residual relative $^{2}$ to $\mathrm{BFC}_{\mathrm{mod}}$ "Silt" and marginally lower values relative to PS1772-8-"Silt" (Fig. 5: Baikal-"Silt" training set). Furthermore, the difference between XRF and FTIR estimates of contamination decreases from $5.6 \%$ to $3.1 \%$ across the whole dataset when using the Baikal-"Silt" model and falls to $2.2 \%$ for samples containing less than $5 \%$ XRF contamination (Fig. 5).

In this instance the improvement when using the Baikal"Silt" model can be attributed to the level of $\mathrm{Al}_{2} \mathrm{O}_{3}$ within diatom frustules. All diatoms naturally contain a small amount of $\mathrm{Al}$, the amount of which has been documented to vary between individual sites (Ellwood and Hunter, 1999; Ellwood and Hunter., 2000; Dixit et al., 2001; Dixit and Van Cappellen, 2002; Gehlen et al., 2002; van Cappellen et al., 2002; Koning et al., 2007). Whereas the $\mathrm{Al}_{2} \mathrm{O}_{3}$ concentrations for $\mathrm{BFC}_{\text {mod }}$ are at the higher range of acceptable values, they remain within published limits (c.f. van Bennekom et al., 1989). Previous work has shown diatom $\mathrm{Al}_{2} \mathrm{O}_{3}$ concentrations for Lake Baikal of $0.15 \mathrm{wt} . \%$ (Swann, 2010). Such concentrations are closer to those of PS1772-8 $\left(\mathrm{Al}_{2} \mathrm{O}_{3}=0.09\right.$ wt.\%) than $\mathrm{BFC}\left(\mathrm{Al}_{2} \mathrm{O}_{3}=2.0\right.$ wt.\%) and may explain why residual values are significant lower for the PS1772-8-"Silt" model than $\mathrm{BFC}_{\text {mod }}$-"Silt". The improved performance of

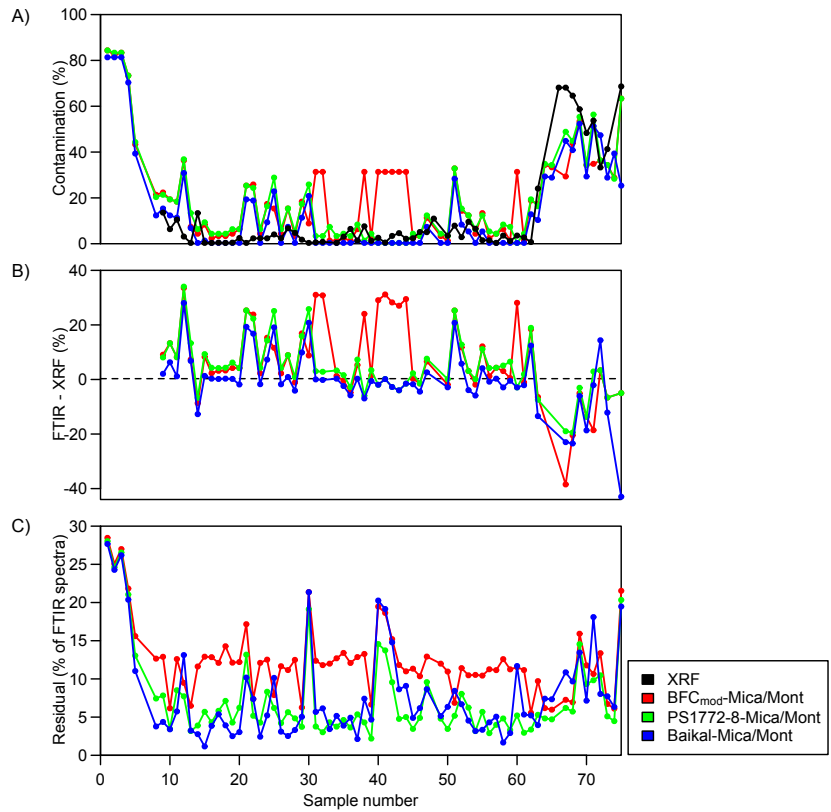

Fig. 7. FTIR three end-member (diatom, mica and montmorillonite) results: (A) FTIR and XRF estimates of contamination in Lake Baikal samples; (B) FTIR minus XRF estimates of contamination. Positive/negative values indicate FTIR over/under-estimation of sample contamination; (C) Residuals $\left(\right.$ Residual $_{c}$ ) from the fitting of the sample FTIR spectra against the best-fit modelled FTIR spectra. No XRF results for some samples indicates the absence of sufficient material for XRF analysis.

the Baikal-"Silt" model over PS1772-8-"Silt" may then reflect the fact that $\mathrm{Al}_{2} \mathrm{O}_{3}$ concentrations in PS1772-8 are half of those of the Baikal diatoms. This suggests that improved model fitting and result accuracy can be be achieved by using diatom/biogenic silica end-members derived from the specific site being analysed, both to account for variations in $\mathrm{Al}_{2} \mathrm{O}_{3}$ /other trace elements as well as for spectral variations caused by the presence of different taxa. This, however, necessitates the need for a more detailed understanding of how diatom $\mathrm{Al}_{2} \mathrm{O}_{3}$ concentrations may vary over time in response to changing environmental conditions.

\subsubsection{Contaminant end-member}

Although the accuracy of the FTIR method improves when using the Baikal-"Silt" model, low-moderate residuals remain from the model fitting that need accounting for. As with the BFC $_{\text {mod }}$ "Silt" and PS1772-8-"Silt" models, an increase in Residual ${ }_{c}$ above c. 7\% results in an increased offset between XRF and FTIR estimated contamination. With these samples linked to increased levels of contamination, as shown by both FTIR and XRF, the accuracy of the "Silt" endmember needs to be examined. Contaminant end-members should be based on residue material that has been removed in the later stages of sample preparation, and so treated in the same manner as far as possible as contaminants in the 
analysed biogenic silica samples. Although this approach is used here with the same FTIR spectra observed for the three samples that comprise the "Silt" end-member, moderate to high residual of up to $19 \%$ suggests that "Silt" is not fully representative of all the sample contaminants (Fig. 5c) and that an alternate, more representative, end-member model be employed.

The development of a three end-member model in an attempt to better simulate the range of clay contaminants results in an improvement in the $\mathrm{BFC}_{\text {mod }}-\mathrm{Mica} / \mathrm{Mont}$ model against XRF estimates of contamination, but fails to significantly improve either the PS1772-8-Mica/Mont or BaikalMica/Mont models or residuals values (Fig. 7c). Indeed in some cases for heavily contaminated samples there is a noticeable deterioration in the residuals and accuracy of FTIR relative to XRF. With the clay mineralogy of Lake Baikal relatively constant over time (Fagel and Mackay, 2008), this implies that other less common aluminosilicates may be forming a large degree of the sample contaminants in addition to other inorganic and organic material. Accordingly, to maximise the accuracy of the future model fitting and so FTIR estimates of contamination, it is necessary to consider in detail how contamination matrices can vary between samples and identify all possible end-members. This is illustrated by recurrent peaks in the two end-member datasets $(n=6)$ when XRF estimates of contamination are low and FTIR estimates are high at 20-40\% (Fig. 5a, b, arrows). All are further marked by significant increases in residual values and replicate sample reproducibility (Fig. 5c). Analysis of these samples under a light microscope reveals moderate amounts of organic matter and micron to sub-micron particle contaminants adhering to the frustule (see Sect. 4.2.1). The high residuals in this instance can therefore be attributed to the absence of an appropriate organic matter end-member in the FTIR calibration.

\subsection{Comparison of the FTIR and XRF methods}

Offsets between XRF and FTIR estimates of contamination, primarily attributed to the difficulty in obtaining a representative contaminant end-member, suggest that the FTIR method may not be suitable for obtaining the precise, quantitative, information required for mass-balance correcting isotope data (e.g., Brewer et al., 2008). In spite of this, results do indicate that this novel FTIR method remains a valuable tool in assessing sample contamination/purity. Firstly, due to the small sample size requirements, with FTIR it proves possible to obtain estimates of sample contamination where insufficient material exists for either XRF analysis or alkaline dissolution experiments. Secondly, visual qualitative analysis of the FTIR sample spectra permits a simple means of identifying samples that are significantly different to the diatom end-member spectra prior to the fitting of the training set data (Fig. 4). Confirmed by XRF estimates of sample contamination, this provides a rapid means of assessing pu- rity before further isotope/geochemical analysis and allows the identification of samples that require additional cleaning without losing material to destructive techniques such as XRF. Thirdly, quantitative changes in FTIR contamination are on average only $2.2 \%$ offset from XRF when contamination is less than 5\% with the FTIR analytical reproducibility over these samples $; 1 \%$ (Fig. 5a). While the offset/error rises with contamination, the FTIR technique nonetheless is able to fully identify the samples as being either clean or contaminated, fulfilling the principal requirement for this method in determining whether a sample is suitable for analysis. Furthermore, when the assumptions made in XRF estimates are considered (see Sect. 4.2.1), it becomes reasonable to assume that FTIR estimates of contamination may actually be as accurate as those from XRF in samples over $95 \%$ clean.

\subsubsection{Limitations of XRF analysis}

A key assumption of this study is that $\mathrm{XRF} \mathrm{Al}_{2} \mathrm{O}_{3}$ measurements are an accurate means of monitoring sample contamination. On the one hand this assumption is usually appropriate as contaminants are often dominated by aluminosilicates. On the other, this is flawed due by the natural presence of small but variable amounts of $\mathrm{Al}_{2} \mathrm{O}_{3}$ in diatoms (see Sect. 4.1.1) that can only be accounted for if the diatom $\mathrm{Al}_{2} \mathrm{O}_{3}$ for the site is known, as is the case with the XRF data presented here (e.g., Mackay et al., 2011a,b). The XRF $\mathrm{Al}_{2} \mathrm{O}_{3}$ method may also be questionable if carbonates or organic matter are prevalent, although high concentrations may be detectable by examining the Loss On Ignition (LOI) during bead fusion at ca. $1050{ }^{\circ} \mathrm{C}$ and $\mathrm{Ca}$ data provided by $\mathrm{XRF}$ analyses, isolating this information from occluded water and other weight losses related to diatom silica exchanges is problematic. The FTIR method circumvents these issues as the spectra of a sample will be affected by all contaminants, regardless of whether they are inorganic or organic in origin, provided that suitable end-members are selected. This includes the presence of any organic matter and water content (for example see Patwardhan et al., 2006) with FTIR further able to differentiate between proteins, which typically mediate biogenic silica formation, and polysaccharides, which are predominantly found as a protective coating for diatoms.

Despite these criticisms, we believe that XRF $\mathrm{Al}_{2} \mathrm{O}_{3}$ in this instance is largely suitable for measuring sample contamination and testing the FTIR method due to light microscopy indicating that aluminosilicates are the main contaminant. As highlighted in (see Sect. 4.1.2), however, this is not the case for all samples with those containing contaminant organic matter marked by low XRF and high FTIR estimates of contamination in addition to erroneously high

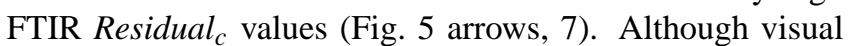
analyses suggest these samples are not $20-40 \%$ contaminated as indicated by FTIR, due to the aforementioned absence of a suitable FTIR organic end-member, some level of contamination is undoubtedly present at levels beyond those 
documented by XRF when using $\mathrm{Al}_{2} \mathrm{O}_{3}$ as a tracer of contamination. Consequently, XRF should not be regarded as a perfect means of assessing sample contamination when organic matter and other volatile compounds are present. Instead a combined XRF and FTIR approach may be optimal for fully identifying samples that contain unacceptable levels of contamination.

\subsection{Implications for palaeoclimatic research}

Diatom and biogenic silica derived isotope and geochemical records are increasingly being identified as important tools in generating climatic and environmental reconstructions at sites where carbonate is not readily preserved in the sediment record. Existing research for example, encompassing both high and low latitude regions, has been marked by investigations using diatom $\delta^{15} \mathrm{~N}$ and $\delta^{30} \mathrm{Si}$ to study the role of the Southern Ocean biological pump and silicic acid leakage in regulating atmospheric $\mathrm{CO}_{2}$ over glacial-interglacial cycles (Beucher et al., 2007). Similarly, the use of diatom $\delta^{18} \mathrm{O}$ has led to the detection of hydrological changes in both Africa and Scandinavia (Barker et al., 2007; Jonsson et al., 2010) while diatom $\mathrm{Zn} / \mathrm{Si}$ ratios are beginning to be developed as proxies in both marine and non-marine settings (Hendry and Rickaby, 2008; Jaccard et al., 2009).

Although the vast majority of these records are valid, in some instances it has been demonstrated that analysed sequences have been contaminated by non-diatom material (Brewer et al., 2008). This can severely inhibit attempts to generate the accurate records required for quantitative reconstructions and, more seriously, lead to erroneous climatic interpretations being made. For example in a deglacial Holocene record from Lake Baikal a 5-10\%o decrease in $\delta^{18} \mathrm{O}$, indicating significant changes in lake hydrology and regional Siberian climatology, was subsequently found to almost entirely originate from the presence of micron to sub-micron clay contaminants adhering to diatom frustules (Morley et al., 2005; Brewer et al., 2008). With even small amounts of contamination capable of varying both geochemical and isotope measurements outside of analytical error, it is necessarily to accurately eliminate such errors and verify the reliability of published data. The demonstration here of a simple quantitative method for identifying unclean samples, contaminated by both organic and non-organic compounds, provides a solution to this and prevents resources being wasted by analysing contaminated samples.

Despite the advances that exist in using FTIR over XRF to assess sample contamination, in particular the ability to detect non-aluminosilicate contaminants, both XRF and FTIR will fail to detect the presence of more than one type of biogenic silica in the analysed sample. For XRF this will be due to the similar, negligible, levels of $\mathrm{Al}_{2} \mathrm{O}_{3}$ in all types of biogenic silica including diatoms, phytoliths and siliceous sponges. For FTIR, it has been shown that such material has a similar spectra to diatoms (Gendron-Badou et al., 2003;
Loucaides et al., 2010). Accordingly, it will remain necessary to continue detecting different types of biogenic silica via microscopy. Since such checks are typically carried out in any instance to determine the taxonomic composition of the analysed samples, the failure of either method to distinguish between different types of biogenic silica should not be an additional burden.

\section{Conclusions}

A simple rapid and non-destructive FTIR technique is presented here detailing a geochemical approach for assessing biogenic silica purity in small, $<1 \mathrm{mg}$, sized samples. With results from this method in line with those from XRF analyses (2.2\% offset when contamination is less than $5 \%)$, the technique is appropriate in instances requiring quick and routine assessments of sample purity, e.g., during sample preparation, and where insufficient materiel exists for other geochemical analyses (e.g., Lake Baikal samples \#18). Such an approach would significantly reduce the time lost by analysing unclean samples for isotope/other geochemical techniques. Issues of sample homogenisation can be resolved in contaminated samples by repeated FTIR analyses of different sub-aliquots of a sample. Further work is needed to apply and test the FTIR method in other sites/samples containing both diatoms and other forms of biogenic silica in order to better understand the methods potential in measuring levels of contamination. In particular, moderate to high residual errors in contaminated samples from the fitting of the FTIR spectra suggest that improvements could be obtained through the identification and use of more refined endmembers for each set of samples. In the interim, by assessing levels of contamination using both FTIR and XRF, the potential limitations associated with each technique can be overcome to provide a better insight of sample contamination. Such steps are essential if mistakes in analysing and interpreting contaminated sequences are to be avoided and biogenic silica isotope/geochemical records are to be used to their full potential in generating reliable palaeoenvironmental reconstructions.

Acknowledgements. This research was funded by a NERC postdoctoral fellowship award to GEAS (NE/F012969/1). SVP gratefully acknowledges the Faculty of Engineering Scholarship from the University of Strathclyde. Thanks are owed to Anson Mackay for providing the diatom samples from Lake Baikal and funds together with the Quaternary Research Associated for the XRF analyses, Simon Kemp for providing the clay mineral standards and Bernhard Chapligin for permitting use of the PS1772-8 diatom standard. Analysed samples were collected as part of the CONTINENT research project (http://continent.gfz-potsdam.de) supported by the European Commission under the Fifth Framework Programme (Contract no. EVK2-2000-00057). Both authors thank the two anonymous reviewers for their constructive comments which helped to improve the quality of the manuscript.

Edited by: T. Kiefer 


\section{References}

Barker, P. A., Leng, M. J., Gasse, F., and Huang, Y.: Century-tomillennial scale climatic variability in Lake Malawi revealed by isotope records, Earth Planet. Sc. Lett., 261, 93-103, 2007.

Beucher, C. P., Brzezinski, M. A., and Crosta, X.: Silicic acid dynamics in the glacial sub-Antarctic: Implications for the silicic acid leakage hypothesis, Global Biogeochem. Cy., 21, GB3015, doi:10.1029/2006GB002746, 2007.

Brewer, T. S., Leng, M. J., Mackay, A. W., Lamb, A. L., Tyler, J. J., and Marsh, N. G.: Unravelling contamination signals in biogenic silica oxygen isotope composition: the role of major and trace element geochemistry, J. Quaternary Sci., 23, 321-330, 2008.

Chapligin, B., Leng, M. J., Webb, W., Alexandre A., Dodd, J.P., Ijiri, A., Lcke, A., Shemesh, A., Abelmann A., Herzschuh, U., Longstaffe, F. J., Meyer, H., Moschen, R., Okazaki, Y., Rees, N., Sharp, Z. D., Sloane, H. J., Sonzogni, C., Swann, G. E. A., Sylvestre F., Tyler, J. J., and Yam, R.: Inter-laboratory comparison of oxygen isotopes from biogenic silica, in preparation, 2011.

Conley, D. J.: Terrestrial ecosystems and the global biogeochemical silica cycle, Global Biogeochem. Cy., 16, 1121-1129, 2002.

De La Rocha, C. L.: Silicon isotope fractionation by marine sponges and the reconstruction of the silicon isotope composition of ancient deep water, Geology, 31, 423-426, 2003.

De La Rocha, C. L.: Opal-based isotopic proxies of paleoenvironmental condition, Global Biogeochem. Cy., 20, GB4S09, doi:10.1029/2005GB002664, 2006.

De La Rocha, C. L., Brzezinski, M. A., and DeNiro M. J.: A first look at the distribution of the stable isotopes of silicon in natural waters, Geochim. Cosmochim. Ac., 64, 2467-2477, 2000.

Derry, L. A., Kurtz, A. C., Ziegler, K., and Chadwick, O. A.: Biological control of terrestrial silica cycling and export fluxes to watersheds, Nature, 433, 728-731, 2005.

Dixit, S. and Van Cappellen, P. A.: Surface chemistry and reactivity of biogenic silica, Geochim. Cosmochim. Ac., 66, 2559-2568, 2002

Dixit. S., Van Cappellen. P. A., and van Bennekom, J.: Processes controlling solubility of biogenic silica and pore water build-up of silicic acid in marine sediments, Mar. Chem., 73, 333-352, 2001.

Dwivedi, N., Arunagirinathan, Sharma, S., and Bellare, J.: FerriteSilica-Insulin Nanocomposites (FeSINC) for Glucose Reduction, Langmuir, 26, 357-361, 2010.

Ellwood, E. J. and Hunter, K. A.: Determination of the $\mathrm{Zn} / \mathrm{Si}$ ratio in diatom opal: a method for the separation, cleaning and dissolution of diatoms, Mar. Chem., 66, 149-160, 1999.

Ellwood, E. J. and Hunter, K. A.: Variations in the $\mathrm{Zn} / \mathrm{Si}$ record over the last interglacial glacial transition, Paleoceanography, 15, 506-514, 2000.

Fagel, N. and Mackay, A. W.: Weathering in the Lake Baikal watershed during the Kazantsevo (Eemian) interglacial: evidence from the lacustrine clay record, Palaeogeogr. Palaeocl., 259, 244-257, 2008.

Fidalgo, A. and Ilharco, L. M.: The defect structure of sol-gelderived silica/polytetrahydrofuran hybrid films by FTIR, J. NonCryst. Solids., 283, 144-154, 2001.

Filippelli, G. M., Carnahan, J. W., Derry, L. A., and Kurtz, A.: Terrestrial paleorecords of $\mathrm{Ge} / \mathrm{Si}$ cycling derived from lake diatoms, Chem. Geol., 168, 9-26, 2000.

Fröhlich, F.: Deep-sea biogenic silica: new structural and analyti- cal data from infrared analysis - geological implications, Terra Nova, 1, 267-273, 1989.

Gehlen, M., Beck, L., Calas, G., Flank, A. M., van Bennekom, A. J., and van Beusekom., J. E. E.: Unraveling the atomic structure of biogenic silica: Evidence of the structural association of $\mathrm{Al}$ and $\mathrm{Si}$ in diatom frustules, Geochim. Cosmochim. Ac., 66, 16011609, 2002.

Gendron-Badou. A., Coradin, T., Maquet, J., Frhlich, F., and Livage, J.: Spectroscopic characterization of biogenic silica, J NonCryst. Solids, 316, 331-337, 2003.

Giddings, J. C.: A system based on split-flow lateral transport thin (SPLITT) separation cells for rapid and continuous particle fractionation, Separ. Sci. Technol., 20, 749-768, 1985.

Hamilton, S. K., Sippel, S., and Bunn, S. E.: Separation of algae from detrius for stable isotope or ecological stoichiometry studies using density fractionation in colloidal silica, Limnol. Oceanogr. Methods, 3, 149-157, 2005.

Hendry, K. R. and Rickaby, R. E. M.: Opal (Zn/Si) ratios as a nearshore geochemical proxy in coastal Antarctica, Paleoceanography, 23, PA2218, doi:10.1029/2007PA001576, 2008.

Hendry, K. R., Geog, R. B., Rickaby, R. E. M., Robinson, L. F., and Halliday, A. N.: Deep ocean nutrients during the Last Glacial Maximum deduced from sponge silicon isotopic compositions, Earth Planet. Sc. Lett., 292, 290-300, 2010

Hodson, M. J., Parker, A. G., Leng, M. J., and Sloane, H. J.: Silicon, oxygen and carbon isotope composition of wheat (Triticum aestivum L.) phytoliths: implications for palaeoecology and archaeology, J. Quaternary Sci., 23, 331-339, 2008.

Jaccard, T., Ariztegui, D., and Wilkinson, K. J.: Assessing past changes in bioavailable zine from a terrestrial $(\mathrm{Zn} / \mathrm{Si})$ opal record, Chem. Geol., 258, 362-267, 2009.

Jonsson, C. E., Andersson, S., Rosqvist, G. C., and Leng, M. J.: Reconstructing past atmospheric circulation changes using oxygen isotopes in lake sediments from Sweden, Clim. Past, 6, 49-62, doi:10.5194/cp-6-49-2010, 2010.

Juillet-Leclerc, A.: Cleaning process for diatomaceous samples, in: Proceedings of the 8th Diatom Symposium, edited by: Ricard, M., Koeltz Scientific Books, Koenigstein, 733-736, 1986.

Koning, E., Gehlen, M., Flank, A. M., Calas, G., and Epping, E.: Rapid post-mortem incorporation of aluminum in diatom frustules: evidence from chemical and structural analyses, Mar. Chem., 103, 97-111, 2007.

Leng, M. J. and Sloane, H. J.: Combined oxygen and silicon isotope analysis of biogenic silica, J. Quaternary Sci., 23, 313-319, 2008.

Leng, M. J., Swann, G. E. A., Hodson, M. J., Tyler, J. J., Patwardhan, S. V., and Sloane, H. J.: The potential use of silicon isotope composition of biogenic silica as a proxy for environmental change, Silicon, 1, 65-77, 2009.

Liu, K., Feng, Q. M., Yang, Y. X., Zhang, G. F., Ou, L. M., and Lu, Y. P.: Preparation and characterization of amorphous silica nanowires from natural chrysotile, J. Non-Cryst. Solids., 353, 1534-1539, 2007.

Loucaides., S., Behrends, T., and van Cappellen, P.: Reactivity of biogenic silica: surface versus bulk charge density, Geochim. Cosmochim. Ac., 74, 517-530, 2010.

Mackay, A. W., Swann, G. E. A., Brewer, T. S., Leng, M. J., Morley, D. W., Piotrowska, N., Rioual, P., and White, D.: A reassessment of late glacial-Holocene diatom oxygen isotope record from Lake 
Baikal using a geochemical mass-balance approach, J. Quaternary Sci., in press, 2011a.

Mackay, A. W., Fagel, N., Leng, M. J., Morley, D. W., Rioual, P., Swann, G. E. A., and Tarasov, P.: A multiproxy approach to reconstructing Last Interglacial environments in central Asia, in preparation, 2011b.

Marcin, M.: fitky. version 0.8.8, http://www.unipress.waw.pl/fityk/, 2009.

Minoletti, F., Hermoso, M., and Gressier, V.: Separation of sedimentary micron-sized particles for palaeoceanography and calcareous nannoplankton biogeochemistry, Nature Protocols, 4, 14-24, 2009.

Morley, D. W., Leng, M. J., Mackay, A. W., Sloane, H. J., Rioual, P., and Battarbee, R. W.: Cleaning of lake sediment samples for diatom oxygen isotope analysis, J. Paleolimnol., 31, 39-401, 2004.

Morley, D. W., Leng, M. J., Mackay, A. W., and Sloane, H. J.: Late Glacial and Holocene environmental change in the Lake Baikal region documented by oxygen isotopes from diatom silica, Global Planet Change., 46, 221-233, 2005.

Moschen, R., Lücke, A., Parplies, J., Radtke, U., and Schleser, G. H.: Transfer and early diagenesis of biogenic silica oxygen isotope signals during settling and sedimentation of diatoms in a temperate freshwater lake (Lake Holzmaar, Germany)., Geochim. Cosmochim Ac., 70, 4367-4379, 2006.

Nayak, P. S. and Singh, B. K.: Instrumental characterization of clay by XRF, XRD and FTIR, Bulletin of Material Science, 30, 235238, 2007.

Opfergelt, S., Delvaux, B., André, L., and Cardinal, D.: Plant silicon isotope signature might reflect soil weathering degree, Biogeochemistry, 91, 163-175, 2008.

Patwardhan, S. V., Maheshwari, R., Mukherjee, N., Kiick, K. L., and Clarson, S. J.: Conformation and Assembly of Polypeptide Scaffolds in Templating the Synthesis of Silica, Biomacromolecules, 7, 491-497, 2006.

Rickert, D., Schlüter, M., and Wallmann, K.: Dissolution kinetics of biogenic silica from the water column to the sediments, Geochim. Cosmochim. Ac., 66, 439-455, 2002.

Rings, A., Lücke, A., and Schleser, G. H.: A new method for the quantitative separation of diatom frustules from lake sediments, Limnol. Oceanogr. Methods, 2, 25-34, 2004.

Robinson, R. S., Brunelle, B. G., and Sigman, D. M.: Revisiting nutrient utilisation in the glacial Antarctic: evidence from a new method for diatom-bound $\mathrm{N}$ isotopic analysis, Paleoceanography, 19, PA3001, doi:10.1029/2003PA000996, 2004.
Rosén, P., Vogel, H., Cunningham, L., Reuss, N., Conley, D. J., and Persson, P.: Fourier transform infrared spectroscopy, a new method for rapid determination of total organic and inorganic carbon and biogenic silica concentrations in lake sediments, J. Paleolimnol., 43, 247-259, 2010.

Schmidt, M., Botz, R., Rickert, D., Bohrmann, G., Hall, S. R., and Mann, S.: Oxygen isotope of marine diatoms and relations to opal-A maturation, Geochim. Cosmochim. Ac., 65, 201-211, 2001.

Shemesh, A., Burckle, L. H., and Hays, J. D.: Late Pleistocene oxygen isotope records of biogenic silica from the Atlantic sector of the Southern Ocean, Paleoceanography, 10, 179-196, 1995.

Street-Perrott, F. A. and Barker, P. A.: Biogenic silica: a neglected component of the coupled global continental biogeochemical cycles of carbon and silicon, Earth Surf. Proc. Land, 33, 1436$1457,2008$.

Swann, G. E. A. and Leng, M. J.: A review of diatom $\delta^{18} \mathrm{O}$ in palaeoceanography, Quaternary Sci. Rev., 28, 384-398, 2009.

Swann, G. E. A., Leng, M. J., Juschus, O., Melles, M., BrighamGrette, J., and Sloane, H. J.: A combined oxygen and silicon diatom isotope record of Late Quaternary change in Lake El'gygytgyn, North East Siberia, Quaternary Sci. Rev., 29, 774786, 2010.

Temuujin, J., Burmaa, G., Amgalan, J., Okada, K., Jadambaa, T., and MacKenzie, K. J. D.: Preparation of porous silica from mechanically activated kaolinite, J. Porous Mat., 8, 233-238, 2001.

Tyler, J. J., Leng, M. J., and Sloane, H. J.: The effects of organic removal treatment on the integrity of $\delta^{18} \mathrm{O}$ measurements from biogenic silica, J. Paleolimnol., 37, 491-497, 2007.

van Bennekom, A. J., Jansen, J. H. F., van der Gaast, S. J., van Iperen, J. M., and Pieters, J.: Aluminum-rich opal: an intermediate in the preservation of biogenic silica in the Zaire (Congo) deep-sea fan, Deep-Sea Res., 36, 173-190, 1989

van Cappellen, P., Dixit, S., and van Bennekom, J.: Biogenic silica dissolution in the ocean: reconciling experimental and field-based dissolution rates. Global Biogeochem. Cy., 16, 1075 , doi:10.1029/2001GB001431, 2002.

Vogel, H., Rosén, P., Wagner, B., Melles, M., and Persson, P. Fourier transform infrared spectroscopy, a new cost- effective tool for quantitative analysis of biogeochemical properties in long sediment records, J. Paleolimnol., 40, 689-702, 2008. 